\title{
DAMPAK FASILITATIF TUMBUHAN LEGUM PENUTUP TANAH DAN TANAMAN BERMIKORIZA PADA SUKSESI PRIMER DI LAHAN BEKAS TAMBANG KAPUR (Facilitative Impacts of Legume Cover-crop and Mycorrhizal-inoculated Plant on Primary Succession of Limestone Quarries)
}

\author{
Retno Prayudyaningsih ${ }^{1}$, Eny Faridah $^{2}$, Sumardi ${ }^{2}$ dan Bambang Hendro Sunarminto ${ }^{3}$ \\ ${ }^{1}$ Balai Penelitian Kehutanan Makassar, Jl. Perintis Kemerdekaan Km.16,5, Makassar, 90242. \\ ${ }^{2}$ Fakultas Kehutanan Universitas Gadjah Mada, Bulaksumur, Yogyakarta, 55281. \\ ${ }^{3}$ Fakultas Pertanian Universitas Gadjah Mada, Jl. Flora 1 Bulaksumur, Yogyakarta, 55281. \\ Penulis korespondensi. Tel: 0411-554049. Email: prayudya93@yahoo.com.
}

Diterima: 17 April 2015

Disetujui: 23 Juni 2015

\begin{abstract}
Abstrak
Penambangan batu kapur dengan metode penambangan terbuka yang meliputi penghilangan vegetasi, pengeboran dan pengebomanan untuk mengeksplotiasi material batu kapur mengakibatkan kerusakan ekosistem. Pemulihan secara alami pada lahan tersebut berjalan lambat karena kondisi tapak dalam proses suksesi tidak mendukung perkembangan vegetasi alaminya. Pembentukan pertanaman diduga memfasilitasi kehadiran tanaman lain melalui perbaikan karateristik lingkungan yang rusak dan/atau peningkatan ketersediaan sumber hara. Dampak fasilitatif pembentukan pertanaman tumbuhan legum penutup tanah (Centrosema pubescens) dan tanaman bermikoriza (Vitex cofassus) dipelajari pada suksesi primer di lahan bekas tambang kapur TNS. Kehadiran tumbuhan alami diukur menggunakan kerapatan individu, keanekaragaman dan jumlah jenis melalui sampling vegetasi dengan metode plot kuadrat secara sistematis berdasarkan tingkat habitusnya. Kondisi tapak diukur berdasarkan ketebalan dan biomasa seresah, kadar bahan organik tanah dan kadar karbon organik tanah. Penelitian dilakukan pada 4 tipe areal di lahan bekas tambang kapur yaitu areal terbuka/kondisi alami tanpa pertanaman, areal pertanaman legum penutup tanah, areal pertanaman tanpa mikoriza dan areal pertanaman bermikoriza. Hasil penelitian menunjukkan pertanaman legum penutup tanah dan pertanaman bermikoriza memperbaiki kondisi tapak lahan bekas tambang kapur. Pembentukan tanaman legum penutup menghasilkan banyak seresah dengan ketebalan 1,08 cm dan biomassa 188,96 g/m² dan dekomposisi selanjutnya meningkatkan bahan organik tanah sebesar 3,80\% dan kandungan karbon organik sebesar 2,20 \%. Pembentukan pertanaman juga memberikan dampak yang sama, khususnya yang diinokulasi Fungi Mikoriza Arbuskula (FMA) menghasilkan seresah dengan ketebalan 1,32 cm dan biomassa 220,48 g/ $\mathrm{m}^{2}$, dengan kadar bahan organik tanah sebesar 3,66\% dan karbon organik tanah sebesar 2,03\%. Perbaikan kondisi tapak tersebut mempercepat kehadiran tumbuhan alami melalui peningkatkan kerapatan individu dan keanekaragaman jenis pada semua tingkatan habitus, meskipun untuk tingkat herba dan semak, kerapatan individu dan keanekaragaman jenis terendah pada areal pertanaman tanpa mikoriza.
\end{abstract}

Kata kunci: bahan organik tanah, dampak fasilitatif, keanekaragaman jenis, mikoriza, suksesi alam.

\begin{abstract}
Limestone mining using open pit mining method that involves vegetation removal and soil drilling and blasting in accessing limestone material has caused ecosystem damages. Natural recovery of such a harsh site is a slow process as the site condition in the successional process do not favor the natural vegetation development. Plants Establishment could facilitate other plants by ameliorating harsh environmental characteristics and/or increasing the availability of nutrient resources. Facilitation impact of legume cover crop (Centrosema pubescens) and mycorrhizal-inoculated plantation (Vitex cofassus) was studied on primary succession of TNS limestone mining quarry. The emergence of natural plants is measured using individual density, diversity and number of species by quadrat systematic plot method base on their habitus. Site conditions measured by litterfall thickness and biomass, soil organic matter content and soil organic carbon levels. The study was conducted in four types of areas on limestone postmining lands are open areas/natural conditions without planting, legume cover crop area, non mycorrhizal-inoculated plant area and mycorrhizal-inoculated plant area. The results indicated, establishment of legume cover crops and mycorrhizalinoculated plants improved site conditions of limestone quarry. Legume cover crops establishment produced a large amount of litters with 1,08 cm of a thickness and 188,96 g/m $\mathrm{m}^{2}$ of biomass, and it's subsequent decomposition increased soil organic matter of 3,80\% and the organic carbon content of 2,20\%. Plantation formation gave similar impact as well, particulary those inoculated with Arbuscula Mycorrhizae Fungi (AMF) produced amount of litters with 1,32 cm of a thickness and 220,48 $\mathrm{g} / \mathrm{m}^{2}$ of biomass, with 3,66\% of soil organic matter content and 2,03\% of soil organic carbon. Improvement of site conditions have accelerated the emergence of a natural plant and resulted in individual density and
\end{abstract}


species diversity on all habitus type, although the least herbs and shrubs were found in area of non mycorrhizalinoculated plantation.

Keywords: facilitative impact, mycorrhiza, primary succession, species diversity, soil organic matter.

\section{PENDAHULUAN}

Suksesi alami merupakan proses penting dalam perkembangan vegetasi, terutama pada lahan yang telah mengalami kerusakan seperti lahan bekas tambang kapur. Setelah penambangan batu kapur sebagai bahan baku pembuatan semen, lahan bekas tambangnya mempunyai karakteristik tapak tanpa top soil, tingkat kepadatan tinggi, miskin hara, pH tinggi dan populasi mikorba tanah rendah. Kondisi tapak yang demikian tidak mendukung pertumbuhan tanaman, sehingga menyebabkan terhambatnya perkembangan vegetasi alami. Pada akhirnya, proses suksesi alami yang terjadi di lahan bekas tambang kapur berjalan sangat lambat.

Proses suksesi yang terjadi pada lahan bekas tambang batu kapur merupakan suksesi primer, karena terjadi pada areal dengan permukaan batuan dan kekurangan bahan organik, serta belum terjadi perubahan oleh aktivitas organisme. Dengan demikian kondisi tapak lahan bekas tambang kapur tidak mendukung kolonisasi tumbuhan alami. Introduksi tumbuhan penutup tanah terutama legume cover crop diperlukan untuk memperbaiki kualitas tapak. Tanaman legum memainkan peran yang signifikan sebagai fasilitor, terutama dalam suksesi alami dengan memperkaya kandungan nitrogen (N) dalam tanah (Gosling, 2005). Tanaman legum mampu memanfaatkan $\mathrm{N}_{2}$ udara hasil bersimbiosis dengan bakteri Rhizobium dan bahan organik yang dihasilkan kaya hara $\mathrm{N}$ yang merupakan hara makro esensial bagi tanaman (Subowo, 2011). Hal ini merupakan faktor pembatas utama pada lahan-lahan bekas penambangan terbuka seperti lahan bekas tambang kapur. Tanaman cover crop juga meningkatkan bahan organik tanah (Steenwerth dan Belina. 2008).

Kolonisasi tumbuhan secara alami pada tapak yang ekstrim seperti lahan bekas tambang kapur juga membutuhkan adaptasi. Salah satunya melalui asosiasi simbiotik antar organisme yaitu mikoriza. yang bertujuan untuk mengatasi kondisi tapak yang marginal terutama serapan hara. Kehadiran fungi mikoriza sebagai salah satu komponen komunitas mikroba tanah mempengaruhi koeksistensi dominan tumbuhan, struktur komunitas dan kemajuan suksesi vegetasi pada lahan yang rusak (Puschel dkk., 2007) seperti lahan bekas tambang kapur. Kehadiran fungi mikoriza mempengaruhi kolonisasi vegetasi di lahan bekas tambang batu bara (Busby dkk., 2011). Dengan demikian diduga fungi mikoriza mempunyai peran penting bagi keberhasilan pertumbuhan tanaman dalam proses suksesi vegetasi di lahan bekas tambang kapur. Penanaman dengan bibit yang diinokulasi mikroba dapat mempercepat proses regenerasi alami pada lahan bekas tambang (Singh dan Jamaluddin, 2011).

Pertanaman memfasilitasi kehadiran tanaman lain secara langsung melalui perbaikan karakteristik lingkungan yang rusak atau meningkatkan ketersediaan sumber hara (Miller, 1994). Kuantitas perubahan dalam lingkungan mikro yang disebabkan oleh adanya pertanaman akan mendukung pertumbuhan dan kelangsungan hidup tanaman jenis yang lain. Tingkat kematian tanaman oak dan pinus yang tumbuh di areal pertanaman Coraria nepalensis menurun 40\%, sedang pertumbuhan tinggi dan diameternya meningkat 15 - 20\% dibanding yang tumbuh pada areal terbuka/tanpa pertanaman (Goel, 2014). Demikian juga, interaksi antara tanaman dengan fungi mikoriza diduga tidak hanya mempengaruhi pertumbuhan tanaman yang diinokulasi tetapi juga mendukung perkembangan komunitas biotik selanjutnya melalui perbaikan kondisi tapak lahan bekas tambang kapur sehingga akan mempercepat proses suksesi alami. Dengan demikian pembentukan pertanaman dan inokulasi fungi mikoriza di lahan bekas tambang kapur diduga memfasilitasi proses suksesi alaminya sehingga dapat berjalan lebih cepat. Tujuan penelitian adalah mengidentifikasi dampak fasilitasi pertanaman tumbuhan legum penutup tanah dan tanaman bermikoriza terhadap suksesi primer di lahan bekas tambang kapur melalui kehadiran jenis-jenis tumbuhan alami berdasarkan struktur habitusnya dan kondisi tapak berdasarkan kandungan bahan organiknya.

\section{METODE PENELITIAN}

\section{Waktu dan Lokasi}

Penelitian dilakukan pada bulan Februari Juni 2014 di lahan bekas tambang kapur PT. TNS, Kabupaten Pangkep, Sulawesi Selatan. Areal lahan bekas tambang kapur PT. TNS yang dijadikan sebagai lokasi penelitian adalah Quarry A seluas 11 ha dan berumur 15 tahun (Gambar 1). Penelitian dilakukan pada 4 tipe lokasi yaitu areal kondisi alami/tanpa pertanaman (T0), areal tumbuhan legum penutup tanah/cover crop (T1), areal pertanaman tidak bermikoriza (T2), dan areal pertanaman bermikoriza (T3). 


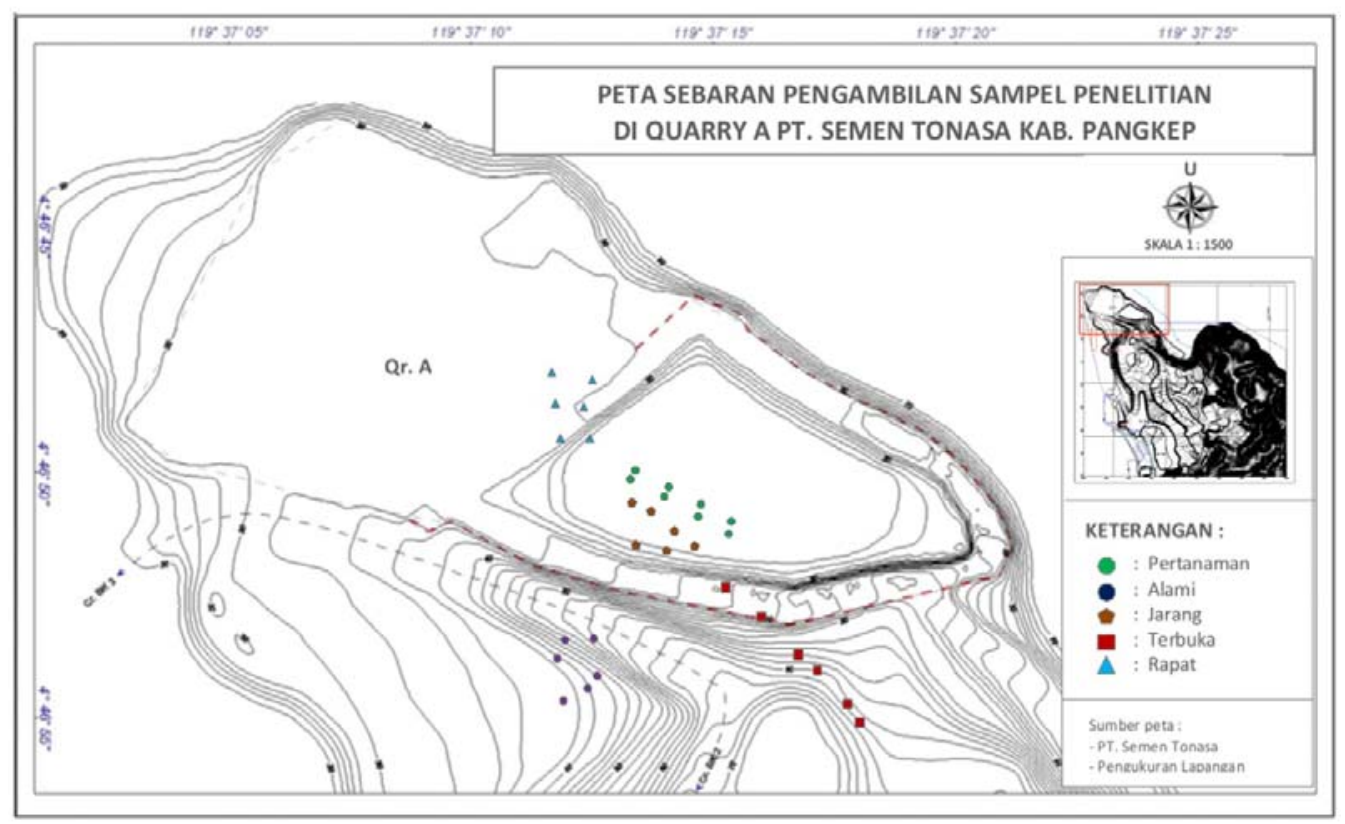

Gambar 1. Peta situasi lahan bekas tambang kapur Quarry A.

Areal kondisi alami/tanpa pertanaman merupakan areal di lahan bekas tambang kapur Quarry A yang belum direklamasi. Areal pertanaman bermikoriza dan tanpa mikoriza merupakan plot pertanaman yang telah dibangun sejak tahun 2010. Perbedaan antara kedua areal tersebut adalah keberadaan inokulasi Fungi Mikoriza Arbuskula (FMA) pada pertanamannya. Areal cover crop merupakan bagian dari areal pertanaman bermikoriza dan tidak bermikoriza.

Areal cover crop dipilih karena pada awal pembentukan areal pertanaman bermikoriza dan tidak bermikoriza, areal tersebut ditanami lebih dulu dengan tanaman legum cover crop yang bertujuan untuk memberikan pra kondisi agar tidak terjadi kekahatan unsur $\mathrm{N}$ dan membentuk iklim mikro di dalam tanah. Areal pertanaman bermikoriza dan tanpa mikoriza, selain ditanami legume cover crop (Centrosema pubescens), juga ditanami jenis sere awal/pioner tingkat pohon (Sesbania sericea) dan jenis sere lanjut (Vitex cofassus). Namun sejak tahun 2011, S. sericea mengalami kematian. Dengan demikian kondisi areal pertanaman bermikoriza dan tanpa mikoriza berupa C. pubescens sebagai cover crop dan $V$. cofassus sebagai sere lanjut (umur 3 tahun)

\section{Bahan dan Alat}

Bahan penelitian yang digunakan adalah sampel tumbuhan, sampel tanah pada kedalaman 0$20 \mathrm{~cm}$ dan sampel seresah. Bahan untuk pengambilan sampel tanah, seresah dan spesimen tumbuhan adalah kantong plastik, karet gelang dan spirtus. Alat-alat penelitian yang digunakan antara lain adalah alat untuk pengambilan sampel tanah dan seresah berupa sekop tanah, pisau, gunting stek dan ice box atau container, serta alat untuk sampling vegetasi meliputi GPS, kompas, meteran, mistar, tali plastik, hand counter, hand sprayer dan sasak herbarium.

\section{Prosedur \\ Sampling vegetasi}

Pembuatan plot pengamatan

Pada setiap tipe lokasi (T0, T1, T2 dan T3) dilakukan sampling vegetasi terhadap tumbuhan alaminya. Sampling vegetasi menggunakan metode plot kuadrat berdasarkan habitus tumbuhannya secara sistematis dengan jalur yang titik awalnya ditentukan secara acak. Pada setiap tipe lokasi dibuat jalur dan pada jalur tersebut diletakkan plot dengan ukuran 1 x $1 \mathrm{~m}$ untuk pengamatan herba, 2 x $2 \mathrm{~m}$ untuk semai dan semak, 5 x $5 \mathrm{~m}$ untuk pancang dan semak dan $10 \times 10 \mathrm{~m}$ untuk tiang dan pohon (Gambar 2). Untuk areal cover crop, plot yang dibuat hanya berukuran 2 x $2 \mathrm{~m}$ dan $1 \times 1 \mathrm{~m}$. Hal tersebut dikarenakan keterbatasan luasan lokasi. Areal cover crop berada di dalam areal pertanaman bermikoriza dan tanpa mikoriza yaitu pada bagian yang tidak ada tanaman sere lanjut $(V$. cofassus).

Sampling vegetasi dilakukan berdasarkan habitus tumbuhannya yaitu herba, semak dan pohon. Menurut Mueller - Dombois dan Ellenberg (1974), herba (herb layer) merupakan lapisan tumbuhan dengan tinggi $<50 \mathrm{~cm}$, semak (shrub layer) merupakan lapisan tumbuhan dengan tinggi antara $50 \mathrm{~cm}-5 \mathrm{~m}$, dan pohon (tree layer) merupakan lapisan tumbuhan dengan tinggi $>5 \mathrm{~m}$. 


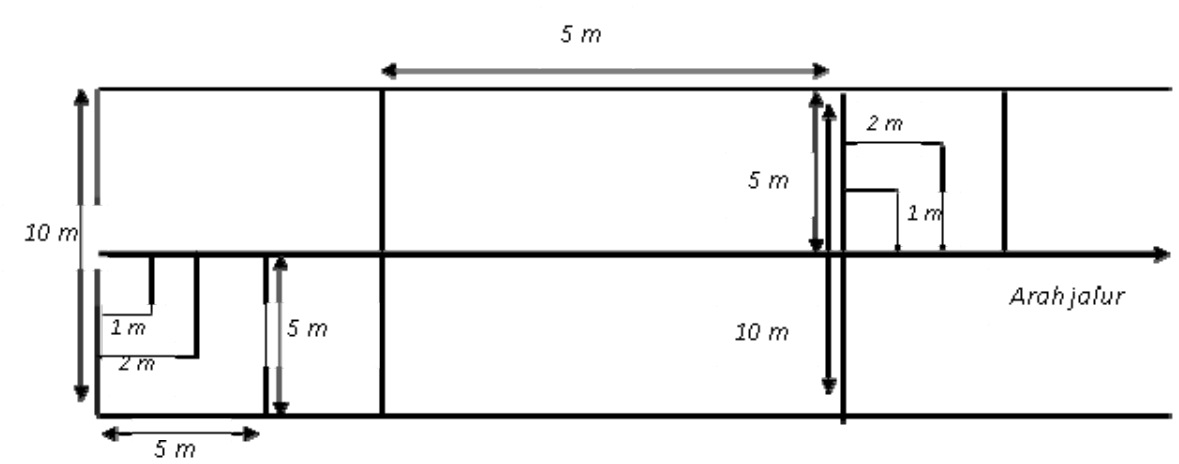

Gambar 2. Denah plot pengamatan sampling vegetasi metode kuadrat secara sistematis dengan jalur dan bentuk petak bersarang.

Pengumpulan data vegetasi

Pada setiap plot di tiap tipe lokasi (T0, T1, T2 dan T3) dilakukan pengamatan terhadap jenis, jumlah individu setiap jenisnya dan tutupan tajuknya (crown cover diameter). Bentuk tajuk/ crown tumbuhan tidak selalu lingkaran sempurna maka pengukuran diameter tajuk dilakukan tidak hanya 1 kali pada 1 sisi tetapi 2 kali pada sisi yang berlainan. Tutupan tajuk (crown cover) selanjutnya dihitung dengan rumus menurut Mueller-Dombois dan Ellenber (1974).

\section{Analisis data}

Data vegetasi yang diperoleh selanjutnya dianalisis untuk mengetahui jumlah jenis, densitas (K), dan indeks keanekaragamannya (H'). Densitas individu dihitung berdasarkan jumlah individu setiap jenis yang jumpai dalam setiap plot pengamatan (Mueller-Dombois dan Ellenberg, 1974; Krebs, 1972). Indeks keanekaragaman (H') dianalisis menggunakan rumus dari Shannon dan Wiener (1949) dalam Krebs (1972).

\section{Sampling seresah dan tanah}

Pengambilan sampel tanah dan seresah

Pengambilan sampel tanah dilakukan di plot 10 x 10 m untuk areal kondisi alami (T0), pertanaman tidak bermikoirza (T2) dan pertanaman bermikoriza (T3), dan di plot 2 x 2 m untuk areal cover crop (T1). Selanjutnya dalam tiap plot diambil sampel tanahnya dari 5 titik, dimana 4 titik dari sudut - sudut plot dan 1 titik dari perpotongan garis diagonal plot (Paetz dan Wilke, 2005). Sebanyak $1 \mathrm{~kg}$ tanah dari tiap titik di dalam plot diambil dengan kedalaman $0-20 \mathrm{~cm}$. Sampel tanah tersebut dimasukkan ke dalam kantong plastik, diberi label dan kemudian dilakukan pengompositan sesuai subplotnya di laboratorium. Sampel tanah yang diambil adalah untuk keperluan analisis kandungan $\mathrm{C}$ organiknya.

Pengambilan sampel seresah juga dilakukan di plot 10 x $10 \mathrm{~m}$ untuk areal kondisi alami, pertanaman bermikoriza dan pertanaman tidak bermikoriza, dan di plot 2 × 2 m untuk areal cover crop. Pada tiap plot dibuat subplot berukuran $25 \mathrm{x}$ $25 \mathrm{~cm}$ (Andreetta dkk., 2013) yang terletak di 4 titik dari sudut-sudut plot dan 1 titik dari perpotongan garis diagonal plot.

Pengamatan dan pengumpulan data

Pengamatan tanah berupa kadar bahan organik tanah (BOT) dan kandungan $\mathrm{C}$ organik tanah melalui analisis kimia tanah dengan metode pengujian Churmies. Pengamatan seresah meliputi ketebalan dan biomassa seresah. Ketebalan seresah/bahan organik diukur dengan cara mengukur ketebalan seresah di tiap subplot $25 \mathrm{~cm} \mathrm{x}$ $25 \mathrm{~cm}$ pada keempat sisinya, kemudian dirata-rata, sedangkan pengamatan terhadap biomasa seresah dilakukan dengan menimbang berat kering contoh bahan organik yang diambil di lokasi penelitian. Seresah dari lapangan ditimbang berat basahnya, selanjutnya dioven pada suhu $80{ }^{\circ} \mathrm{C}$ selama 72 jam untuk mencapai berat kering konstan (Windusari dkk, 2007).

\section{HASIL DAN PEMBAHASAN}

Identifikasi kehadiran tumbuhan alami pada tiap tipe areal di lahan bekas tambang kapur menunjukkan bahwa areal cover crop mempunyai densitas jenis tumbuhan alami tertinggi. Keanekaragaman dan jumlah jenis tumbuhan alami tertinggi ditemukan pada areal pertanaman bermikoriza (Tabel 1).

Tabel 1. Jumlah jenis, densitas, dan indeks keanekaragaman tumbuhan alami yang mengolonisasi lahan bekas tambang kapur.

\begin{tabular}{cccc}
\hline Areal & $\begin{array}{c}\text { Jumlah } \\
\text { Jenis/ } \\
\text { plot }\end{array}$ & $\begin{array}{c}\text { Densitas (K) } \\
\text { individu/m }\end{array}$ & $\begin{array}{c}\text { Indeks } \\
\text { Keanekaragaman } \\
\left(\mathrm{H}^{\prime}\right)\end{array}$ \\
\hline T0 & 21 & 845,62 & 0,55 \\
T1 & 35 & $\mathbf{3 5 9 5 , 0 0}$ & 2,52 \\
T2 & 22 & 599,25 & 0,83 \\
T3 & $\mathbf{4 3}$ & 3074,91 & $\mathbf{3 , 3 1}$ \\
\hline
\end{tabular}

Sumber : Hasil analisis. Keterangan : T0 (areal kondisi alami), T1 (areal cover crop), T2 (areal pertanaman tanpa mikoriza), dan T3 (areal pertanaman bermikoriza). 
Tabel 2. Jumlah jenis, densitas, dan indeks keanekaragaman jenis tumbuhan alami yang mengolonisasi lahan bekas tambang kapur berdasarkan tipe habitusnya.

\begin{tabular}{lcccc}
\hline \multicolumn{1}{c}{ Habitus } & Areal & Jumlah jenis/plot & Kerapatan satuan (ind $\left./ \mathrm{m}^{2}\right)$ & Indeks keanekaragaman (H') \\
\hline 1. Rumput & T0 & 4 & 200,99 & 0.07 \\
& T1 & 9 & $\mathbf{1 0 7 6 , 2 5}$ & 0,58 \\
& T2 & 4 & 205,00 & 0.46 \\
& T3 & $\mathbf{1 2}$ & 846,91 & $\mathbf{1 , 0 5}$ \\
\hline 2. Herba & T0 & 12 & 647,28 & $\mathbf{1 , 3 1}$ \\
(termasuk fern) & T1 & 17 & $\mathbf{2 4 3 8 , 0 0}$ & 0,25 \\
& T2 & 11 & 377,28 & 1,46 \\
\hline 3. Semak & T3 & $\mathbf{2 1}$ & 2164,00 & 0.16 \\
& T0 & 2 & 52,84 & 0,14 \\
& T1 & 2 & $\mathbf{7 5 , 7 5}$ & 0,11 \\
& T2 & 2 & 14,44 & $\mathbf{0 , 6 2}$ \\
\hline 4. Pohon & T3 & 2 & 57,96 & 0.01 \\
& T0 & 3 & 1,50 & 0.02 \\
& T1 & 6 & 5,00 & 0.01 \\
& T2 & 5 & 2,25 & $\mathbf{0 . 0 2}$ \\
\hline
\end{tabular}

Sumber : Hasil analisis. Keterangan : T0 (areal kondisi alami), T1 (areal cover crop), T2 (areal pertanaman tanpa mikoriza), dan T3 (areal pertanaman bermikoriza).

Identifikasi kehadiran tumbuhan alami berdasarkan struktur habitusnya menunjukkan semua tingkat habitus (rumput, herba, semak dan pohon) ditemukan tumbuh di lahan bekas tambang kapur. Tabel 2 menunjukkan areal cover crop memiliki kerapatan jenis tumbuhan rumput, herba dan semak tertinggi, diikuti areal pertanaman bermikoriza, tanpa pertanaman dan pertanaman tanpa mikoriza. Pada tingkat habitus pohon, areal pertanaman bermikoriza mempunyai kerapatan individu tertinggi. Ditinjau dari keanekaragaman dan kelimpahan jenisnya (Tabel 2 dan Lampiran 1), areal pertanaman bermikoriza memiliki nilai lebih tinggi dibanding areal lainnya, baik pada tingkat herba, rumput, semak dan pohon.

Sedikitnya jenis tumbuhan alami dari semua tipe habitus yang ditemukan pada lahan bekas penambangan batu kapur (areal tanpa pertanaman) menunjukkan bahwa kolonisasi spontan jenis alami pada suksesi primer terjadi sangat lambat. Sampai dengan 15 tahun setelah selesainya kegiatan penambangan, lahan bekas tambang kapur tersebut masih didominasi oleh 4 jenis rumput, 12 jenis herba, sedangkan jenis-jenis semak dan pohon masing-masing hanya berjumlah 2 dan 3 jenis saja. Ketersediaan sumber benih alami di sekitar areal penambangan bukan merupakan hambatan, karena vegetasi alami (hutan alam yang belum ditambang) yang ada hanya berjarak kurang dari $1 \mathrm{~km}$ dari areal bekas tambang yang diteliti. Kondisi tapak lahan bekas tambang kapur yang sangat tidak mendukung pertumbuhan tanaman merupakan faktor pembatas perkembangan suksesi awal. Kondisi tanah hanya meninggalkan lapisan batuan sebagai bahan induk tanah yang sangat miskin hara $(\mathrm{pH}=8,14$; C-org= $1,75 \%$; $\mathrm{N}$ total $=0,12 \%$; bahan organik $=0,10 \%$; $\mathrm{P}$ tersedia $=19,2 \mathrm{ppm}$ dan $\mathrm{Ca}=115,75 \mathrm{me} / 1000 \mathrm{~g}$ )
(Prayudyaningsih, 2008; Singh dan Jamaluddin, 2011). Metode penambangan terbuka seperti penambangan batu kapur memang telah banyak dibuktikan meninggalkan kondisi tapak yang sangat tidak mendukung pertumbuhan jenis-jenis tumbuhan suksesi awal (Hazarika, 2006; Tropek dkk., 2010; Singh, 2011; Cohen-Fernandez dan Naeth, 2013).

Keberhasilan vegetasi dalam mengolonisasi suatu lahan pada proses suksesi tercapai apabila telah terbentuk tapak aman pada lahan tersebut (Lawrence dan Roger, 2008). Tapak aman merupakan kondisi dimana sifat fisik, kimia atau biologi tanah dapat mendukung pertumbuhan vegetasi. Hasil penelitian di lahan bekas tambang kapur menunjukkan adanya introduksi tumbuhan legum penutup tanah dan pertanaman bermikoriza meningkatkan kualitas tanah ditinjuau dari kimia tanahnya terutama kandungan bahan organik (Gambar 3). Pembentukan tapak aman akan menentukan keberhasilan kolonisasi dan pertumbuhan sehingga mendukung berlangsungnya suksesi yang dipercepat dan keberhasilan kegiatan reklamasi lahan bekas tambang kapur.

Pada Gambar 3, kondisi tapak di lahan bekas tambang kapur ditinjau dari kadar karbon (C) organik tanah, kadar bahan organik (BO) tanah, ketebalan dan biomassa seresah menunjukkan bahwa areal cover crop (T1) dan pertanaman bermikoriza (T3) mempunyai kualitas yang lebih baik dari pada areal tanpa mikoriza dan tanpa pertanaman. Kadar C organik dan BO tanah pada areal cover crop (T1) lebih tinggi dibanding areal pertanaman bermikoriza (T3) walaupun tidak berbeda nyata. Namun ditinjau dari ketebalan seresah dan biomassa seresahnya, areal pertanaman 


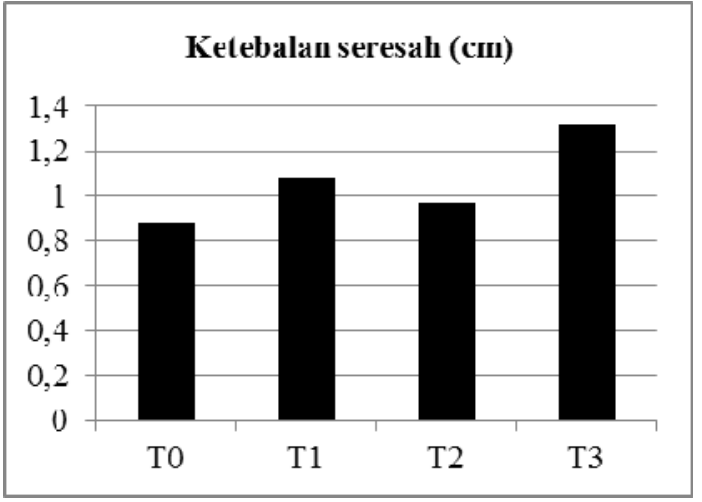

(a)

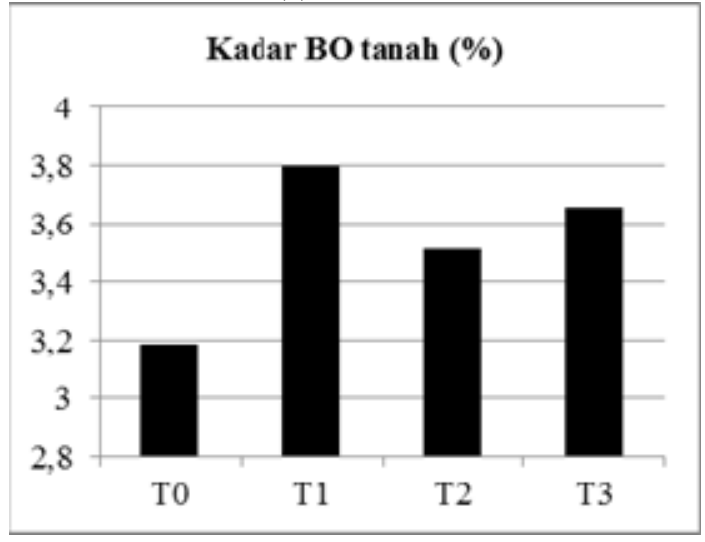

(c)

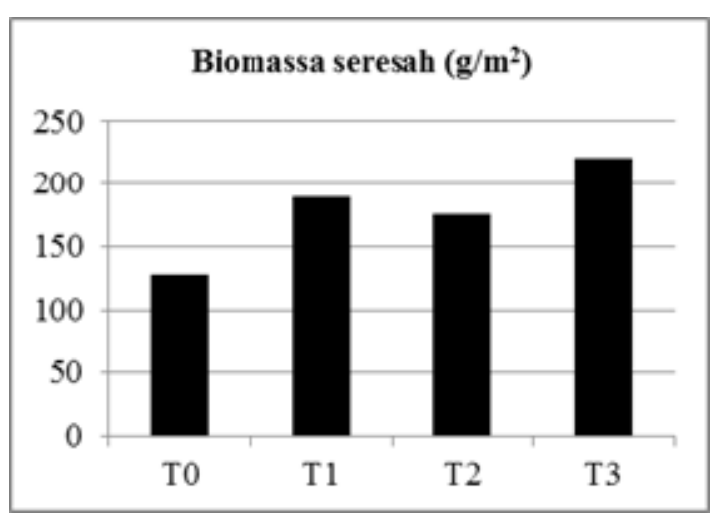

(b)

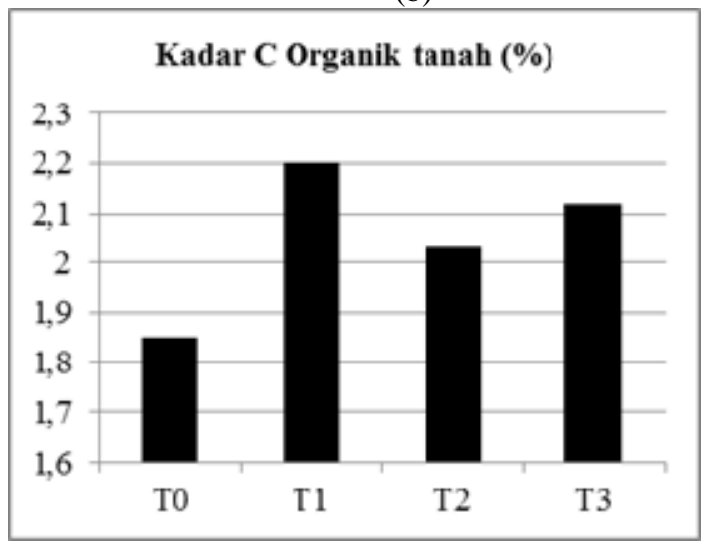

(d)

Gambar 3. Kondisi tapak lahan bekas tambang kapur pada tipe areal yang berbeda berdasarkan (a) ketebalan seresah, (b) biomassa seresah, (c) kadar BO tanah dan (d) kadar karbon organik tanah. Keterangan : T0 (areal kondisi alami), T1 (areal cover crop), T2 (areal pertanaman tanpa mikoriza), dan T3 (areal pertanaman bermikoriza).

bermikoriza (T3) secara signifikan lebih tinggi dibanding areal cover crop (T1).

Pada areal cover crop (T1) kadar BO tanah dan karbon organik tanahnya lebih tinggi dibanding areal lainnya. Jenis tanaman cover crop yang ditanam adalah tanaman legum (C. pubescen) yang merupakan tanaman dengan $\mathrm{C} / \mathrm{N}$ rasio rendah sehingga tidak memerlukan proses dekomposisi yang lama dan komplek (Ding dkk., 2006). Pada areal pertanaman bermikoriza (T3), ketebalan dan biomassa seresah lebih tinggi dibanding areal lainnya. Pada areal ini selain terdapat tumbuhan penutup tanah (C. pubescen), juga terdapat tanaman sere lanjut $V$. cofassus yang diinokulasi FMA.

Lapisan tumbuhan penutup tanah (C. pubescens) yang telah berkembang menunjukkan indikasi kontribusinya terhadap kesuburan tanah. Kontribusi yang paling terlihat berupa terbentuknya lapisan seresah setebal $1,08 \mathrm{~cm}$ atau sebanyak $188,96 \mathrm{~g} / \mathrm{m}^{2}$ pada permukaan tanah. Peran lebih lanjut terhadap kesuburan tanah ditunjukkan oleh peningkatan kadar karbon organik dalam tanah di bawah lapisan tumbuhan penutup tanah ini. Tanaman cover crop mempengaruhi bahan organik tanah (Steenwerth dan Belina, 2008). Selanjutnya Ding dkk. (2006) dan Nascente dkk. (2013) menyatakan bahwa penggunaan tanaman cover crop meningkatkan kadar karbon organik tanah.

Pembentukan lapisan seresah yang tinggi pada permukaan tanah terjadi pada areal di bawah tanaman $V$. cofassus bermikoriza. Pembentukan asosiasi mikorisa pada akar-akar tanaman $V$. cofassus mempunyai peran yang cukup tinggi dalam peningkatan kandungan bahan organik dan karbon organik tanah. Hal ini terlihat dari lebih besarnya peningkatan kedua elemen tanah tersebut dibanding peningkatan pada tanah yang sama tetapi tanpa inokulasi mikoriza. Tanaman $V$. cofassus yang diinokulasi FMA memiliki biomassa daun lebih tinggi dibanding tanaman yang tidak diinokulasi FMA (Prayudyaningsih dkk., 2014). Jumlah biomassa yang banyak ini akan menyumbangkan bahan organik pada tanah yang lebih banyak pula. Nadporozhskaya dkk. (2006) menyatakan bahwa akumulasi karbon dalam bahan organik memacu proses pembentukan tanah pada semua ekosistem hutan. Perubahan fisiko-kimia yang terjadi akibat pembentukan tanaman awal akan memberikan kondisi tapak yang sesuai bagi 
pertumbuhan tanaman lain, terlebih apabila pertanaman tersebut diberi inokulum mikroba (Singh dan Jamaluddin, 2011; Singh, 2011). Kehadiran mikroba tanah seperti fungi mikoriza juga meningkatkan toleransi tumbuhan terhadap kondisi tapak yang tidak menguntungkan (Buscot, 2015) sehingga dapat mendukung kolonisasi tumbuhan di lahan bekas tambang kapur.

Peningkatan kesuburan tanah akibat penanaman jenis tumbuhan legum penutup tanah (C. pubescens) dan tanaman $V$. cofassus bermikoriza dapat memberikan fasilitas terhadap perubahan struktur dan jenis alami yang tumbuh pada tahap suksesi awal di lahan bekas tambang batu kapur. Dampak fasilitatif tersebut ditunjukkan oleh peningkatan kekayaan dan keanekaragaman jenis pada semua tingkatan habitus jenis tumbuhan alami yang tumbuh secara spontan. Lahan bekas tambang kapur yang berumur 5 - 10 tahun mempunyai tingkat kesuburan tanah (kondisi tapak) yang lebih baik dibanding yang baru ditinggalkan (0 tahun), dimana kadar $\mathrm{N}$ meningkat 90\%, $\mathrm{P}$ tersedia meningkat 300\%, kadar bahan organik meningkat $120 \%$, sedang $\mathrm{pH}$ menurun dari 8,5 menjadi 8,2 (Singh dan Jamaluddin, 2011). Untuk regenerasi tumbuhan alaminya, areal pertanaman yang diinokulasi fungi mikoriza mempunyai kelimpahan individu lebih tinggi dibanding areal yang tidak ditanami (Singh, 2011). Hazarika dkk. (2006) menyatakan bahwa keanekaragaman jenis tumbuhan secara alami semakin meningkat pada lahan bekas tambang batubara yang semakin tua umurnya atau telah mengalami suksesi lebih lanjut. Keanekaragaman jenis tumbuhan dapat dijadikan sebagai salah satu indikator terjadinya dampak fasilitatif pada proses suksesi alami. Menurut Wang dkk. (2006), keanekaragaman jenis semakin meningkat seiring dengan peningkatan tahapan suksesi alami yang terjadi pada suatu komunitas. Noragaina (2008) menyatakan lahan bekas tambang batu bara yang telah ditanami mempunyai kekayaan dan kelimpahan jenis tumbuhan alami yang tinggi, sedangkan lokasi lahan tambang yang tidak ditanami mempunyai kekayaan dan kelimpahan jenis yang rendah walaupun dengan umur lahan bekas tambang yang lebih lama.

Kondisi lahan bekas tambang kapur yang terbuka menciptakan kondisi lingkungan mikro yang tidak mendukung perkembangan jenis-jenis tumbuhan alami. Hal tersebut ditunjukkan oleh kerapatan individu per $\mathrm{m}^{2}$ yang rendah pada semua tingkatan habitus. Kondisi lingkungan mikro yang terbuka menyebabkan penguapan yang tinggi akibat radiasi sinar matahari yang tinggi (Goel, 2014). Pada perkembangannya, tumbuhan penutup tanah (C. pubenscens) telah membentuk lapisan tumbuhan bawah yang cukup rapat. Lapisan tersebut menciptakan naungan yang memfasilitasi perkembangan jenis-jenis pioner awal (rumput, herba dan semak) sehingga menghasilkan kerapatan individu paling tinggi. Naungan yang diciptakan oleh tumbuhan penutup tanah sekaligus juga menghambat terjadinya evapotranspirasi berlebihan sehingga menghasilkan kondisi yang lebih lembab (Goel, 2014).

Dampak fasilitatif yang lebih besar terlihat pada perkembangan jenis-jenis rumput (graminoid) dan herba, di samping dampak yang juga terjadi pada jenis-jenis semak dan pohon walaupun tidak sebesar dampak fasilitatif dari kedua tipe habitus terdahulu. Berdasarkan peningkatan sebagian besar tipe habitus tumbuhan alami pada tahap suksesi awal, dapat dikatakan bahwa dampak fasilitasi oleh tumbuhan penutup tanah dan tanaman bermikoriza menentukan komposisi dan struktur jenis-jenis tumbuhan alami yang tumbuh secara spontan di lahan bekas tambang batu kapur. Pembentukan lapisan seresah yang cepat merupakan faktor yang menentukan perkembangan jenis-jenis tumbuhan penyusun suksesi awal pada lahan bekas tambang kapur.

\section{KESIMPULAN}

Penanaman tanaman legum penutup tanah mempercepat dan meningkatkan kandungan bahan organik dan karbon organik tanah melalui akumulasi seresah. Hal yang sama juga terjadi akibat penanaman tanaman yang diinokulasi mikoriza. Areal pertanaman bermikoriza menghasilkan seresah dengan ketebalan $1,32 \mathrm{~cm}$ dan biomassa 220,48 $\mathrm{g} / \mathrm{m}^{2}$, dengan kadar bahan organik tanah sebesar 3,66\% dan karbon organik tanah sebesar 2,03\%. Peningkatan kandungan bahan organik dan karbon organik tanah tersebut memfasilitasi perbaikan tapak di lahan bekas tambang kapur.

Hal tersebut selanjutnya mempercepat kemunculan jenis-jenis alami pada semua tingkatan habitus melalui peningkatkan kerapatan individu dan keanekaragaman jenis pada semua tingkatan habitus. Kerapatan individu jenis-jenis tumbuhan alami akibat penanaman tanaman legum penutup tanah sebesar 3.595 per $\mathrm{m}^{2}$ dengan indek keanekaragaman sebesar 2,52. Kerapatan individu jenis-jenis tumbuhan alami akibat penanaman tanaman yang diinokulasi mikoriza sebesar 3.074,95 per $\mathrm{m}^{2}$ dengan indek keanekaragaman sebesar 3,31. 


\section{UCAPAN TERIMAKASIH}

Ucapan terima kasih kepada PT. Semen Tonasa atas kerja samanya sehingga penelitian ini dapat terlaksana. Selain itu ucapan 'terima kasih juga diberikan kepada Hermin Tikupadang, Edi Kurniawan, Hajar, Mustapa dan Andi Sri Rahmadania yang telah membantu dalam pelaksanaan penelitian dan proses pengumpulan data.

\section{DAFTAR PUSTAKA}

Andreetta, A., Macci, C., Giansoldati, V., Masciandaro, G., dan Carnicelli, S., 2013. Microbial Activity and Organic Matter in Mediterranean Humus Form. Geoderma, 209210:198-208.

Busby, R.R., Gebhart, D.L., Stromberger, M.E., Meiman, P.J., dan Paschke, M.W., 2011. Early Seral Plant Species Interactions with an Arbuscular Mycorrhizal Fungi Community are Highly Variable. Applied Soil Ecology; 48:257-262.

Buscot, F., 2015. Implication of Evolution and Diversity in Arbuscular and Ectomycorrhizal Symbioses. Journal of Plant Physiology, 172:55-61.

Cohen-Fernandez, A.C., dan Naeth, M.A., 2013. Increasing Woody Species Diversity for Sustainable Limestone Quarry Reclamation in Canada. Sustainability, (5):1340-1355.

Ding G., Liu, X., Hebert, S., Novak, J., Amarasiringwardena, D., dan Xing, B., 2006. Effect Cover Crop Management on Soil Organic Matter. Geoderma, 130:229-239.

Goel D., 2014. Facilitative Effects of Coriaria nepalensis on Tree Seedling at Degraded and Eroded Sites. International Journal of Advanced Research, 2(6):295-299.

Gosling P., 2005. Facilitation of Urtica doica Colonization by Lupinus arboreus on A Nutrient-Poor Mining Spoil. Plant Ecology, 178(2):141-148.

Hazarika, P., Talukdar, N.C., dan Singh, Y.P., 2006. Natrual Colonization of Plant Species on Coal Mine Spoils at Tikak Colliery, Assam. Tropical Ecology, 47(1):37-46.

Krebs, C.J., 1972. Ecology: The Experimental Analysis of Distribution Abudance, Harper International Edition, Singapore, pp 506-507.

Lawrence, W. dan Roger, del M., 2008. Lessons from Primary Succession for Restoration of Severely Damaged Habitats. Applied Vegetation Science, 12:55-67.
Miller, T.E., 1994. Direct and Indirect Species Interaction in An Early Old-field Plant Community. The American Naturalist, 143(6):1007-1025.

Mueller-Dombois, D., dan Ellenberg, H., 1974. Aims and Methods of Vegetation Ecology, John Wiley \& Sons, Inc. Toronto. pp 81, 113119.

Nadporozhskaya, M.A., Mohrenb, G.M.J., Chertov, O.G., Komarov, A.S., dan Mikhailov, A.V., 2006. Dynamics of Soil Organic Matter in Primary and Secondary Forest Succession on Sandy Soils in The Netherlands: An Application of the ROMUL Model. Ecological Modelling, 190:399-418.

Nascente, A.S., Li, Y.C., dan Crusciol, C.A.C., 2013. Cover Crops and No-till Effects on Physical of Soil Organic Matter. Soil \& Tillage, 130:52-57.

Noragaina, 2008. Analisis Vegetasi Pada Lahan Bekas Penambangan Batu Bara di Kabupaten Balangan Kalimantan Selatan. Tesis. Fakultas Biologi, Universitas Gadjah Mada, Yogyakarta, pp.42-48.

Paetz, A., dan Wilke, B.M., 2005. Soil Sampling and Storage, dalam R. Margesin and F. Schinner (eds): Manual for Soil AnalisysMonitoring and Assessing Soil Bioremediation. Springer-Verlag, Berlin, pp. $1-44$.

Prayudyaningsih, R., 2008. Keragaman Fungi Mikoriza Arbuskula (FMA) di Lahan Bekas Tambang Kapur, PT. Semen Tonasa dan Efektivitasnya Terhadap Pertumbuhan Semai Kersen (Muntingia calabura L.). Tesis, Fakultas Kehutanan, Universitas Gadjah Mada. Yogyakarta. pp 47-50.

Prayudyaningsih, R., Tikupadang, H., Syarif, M., Kurniawan, E., dan Toaha, A.Q., 2014. Bioprospeksi Fungi Mikoriza Arbuskula (FMA) untuk Reklamasi Lahan Bekas Tambang Kapur. Laporan Hasil Penelitian, Balai Penelitian Kehutanan, Makassar, pp .1415.

Puschel, D., Rydlova, J., dan Vosatka, M., 2007. Mycorrhiza Influence Plant Community Structure in Succession on Spoil Bank. Basic and Applied Ecology, 8:510-520.

Singh, A.J., 2011 Catalityc Effect of Plantation and Microbial Inoculation in Natural Regeneration on Limestone Mined Spoil. The IIOAB Journal, 2(8):24-26.

Singh, A.J., dan Jamaluddin, 2011. Status and Diversity of Arbuscular Mycorrhizal Fungu and Its Role in Natural Regeneration on 
Limestone Mined Spoils. Biodiversitas, 12(2):107-111.

Steenwerth, K., dan. Belina, K.M., 2008. Cover Crop Enhanced Soil Organic matter, Carbon Dynamics and Microbiological Function in a Vineyard Agroecosystem. Applied Soil Ecology, 40:359-369.

Subowo, G., 2011. Penambangan Sistem Terbuka Ramah Lingkungan dan Upaya Reklamasi Pasca Tambang untuk Memperbaiki Kualitas Sumberdaya Lahan dan Hayati Tanah, Jurnal Sumberdaya Lahan; 5(2):83-94.

Tropek, R., Kadlec, T., Karesova, P., Spotzer, L., Kocarek, P., Malenovsky, I., Banar, P., Tuf, I.H., Hedja, M., dan Konvicka, M., 2010. Spontaeous Succession in Limestone Quarries as An Effecive Restoration Tool for Endangered Arthoropods and Plants. Journal of Applied Ecology, 47:139-147.

Wang, D.P, Ji, S.Y., Chen, F.P., Xing, F.W., dan Peng, S.L., 2006. Diversity and Relationship with Succession of Naturally Regenerated Southhern Subtropical Forest in Shenzhen, China dan Its Comparison with The Zonal Climax of Hong Kong. Forest Ecology and Management, 222:384-390.

Windusari, Y., Sari, N.P., Yustian, I., dan Zulkifli, H., 2012. Cadangan Karbon Biomassa Tumbuhan Bawah dan Seresah di Kawasan Suksesi Alami pada Area Pengendapan Tailing PT Freeport Indonesia. Biospecies, 5(1):22-28.

Lampiran 1. Jenis tumbuhan alami yang tumbuh spontan pada setiap tipe areal di lahan bekas tambang kapur berdasarkan tipe habitusnya. (Dapat diakses di : OJS). 